\title{
Yenilenebilir Enerji Üretiminde Mikrobiyal Biyoproseslerin Kullanımı
}

\author{
Ülküye Dudu Gül $1^{*}$, Gizem Bayazıt ${ }^{2}$ \\ 1*Bilecik Şeyh Edebali Üniversitesi, Mühendislik Fakültesi, Biyomühendislik Bölümü, Bilecik, Türkiye,(ORCID: 0000-0001-6443-1633), \\ ulkuyedudu.gul@bilecik.edu.tr \\ ${ }^{2}$ Bilecik Şeyh Edebali Üniversitesi, Lisansüstü Eğitim Enstitüsü, Biyoteknoloji Anabilim Dalı, Bilecik, Türkiye, (ORCID: 0000-0003-2247-3506), \\ gizemkirimli88@gmail.com
}

(1st International Conference on Applied Engineering and Natural Sciences ICAENS 2021, November 1-3, 2021)

(DOI:10.31590/ejosat.1013441)

\begin{abstract}
ATIF/REFERENCE: Gül, Ü. D. \& Bayazıt, G. (2021). Yenilenebilir Enerji Üretiminde Mikrobiyal Biyoproseslerin Kullanımı. European Journal of Science and Technology, (28), 1312-1316.

$\ddot{O} \mathbf{z}$

Artan nüfus ve sanayileşme ile birlikte enerji taleplerindeki hızlı artış tüm dünya ülkelerinde endişe oluşturmaktadır. Mevcut senaryoda konvensiyonel enerji kaynaklarının sınırlı mevcudiyeti ve yenilenemeyen fosil yakıtların hızla tükenmesi nedeniyle dünya oldukça büyük bir enerji krizine tanıklık etmektedir. Bu bağlamda artan nüfus, küresel 1sınma ve sera gazı emisyonları gibi tehlikeli çevresel sorunların üstesinden gelinmesi için dünyanın enerji gereksinimlerini karşılayabilecek alternatif yenilenebilir yakıtların araştırılmasına ihtiyaç duyulmaktadır. Son zamanlarda bakteriler ve algler gibi mikroorganizmaların kullanımı ile organik bileşiklerde saklı kimyasal enerjinin elektrik enerjisine dönüştürülmesi gibi konulara yönelik çalışmalara ilgi artmaktadır. Günümüzde mikrobiyal metabolik faaliyetlerle (özellikle çok çeşitli biyokütle ve biyolojik substratların kullanımı) yenilenebilir enerji üretimi enerji kıtlığı sorununa pratik bir çözüm olarak kabul edilmektedir. Mikrobiyal yakıt hücreleri organik bileşiklerde toplanmış enerjiyi oksitlemek suretiyle katalizleyerek biyoelektriğe dönüştürebilmektedir. Ayrıca mikroorganizmalar doğal metabolik faaliyetleri ile enerji kaynağ olarak kullanılabilecek ürünlerde üretebilmektedirler. Bu duruma örnek olarak birçok mikroorganizmanın karbonhidratları kolayca alkole dönüştürebilme yeteneğini verebiliriz. Bununla birlikte, mikrobiyal yakıt teknolojileri güvenilirliği, yüksek verimliliği, temizliği ve minimum düzeyde toksik veya tamamen toksik olmayan yan ürünler üretmesi gibi avantajlara sahiptir. Bu avantajlar nedeniyle yenilenebilir enerji üretimi için alternatif bir kaynak olarak mikrobiyal yakıt teknolojisinin kullanılması son dönemlerde ileri teknolojik biyoprosesler arasında yer almaktadır. Bu çalışmanın amacı mikroorganizmalar kullanımı ile biyoyakıt ve biyoenerji üretim tekniklerinin kilit noktalarını vurgulamak ve mikrobiyal biyoproseslerle enerji üretiminin faydalarını incelemektir.
\end{abstract}

Keywords: Biyokütle, Biyoyakıt, Metabolik Mühendislik, Biyoenerji, Yenilenebilir Enerji.

\section{Use of Microbial Bioprocesses in Renewable Energy Production}

\begin{abstract}
With the increasing population and industrialization, the rapid increase in energy demands is a great concern in all countries of the world. In the current scenario, the world is witnessing a major energy crisis due to the limited availability of conventional energy sources and the rapid depletion of non-renewable fossil fuels. In this context, there is a need to search for alternative renewable fuels that can meet the world's energy needs in order to overcome dangerous environmental problems such as increasing population, global warming and greenhouse gas emissions. Recently, there has been an increasing interest in studies on the use of microorganisms such as bacteria and algae to convert of chemical energy stored in organic compounds into electrical energy. Today, renewable energy generation by microbial metabolic activities (especially the use of a wide variety of biomass and biological substrates) is considered a practical solution to the problem of energy scarcity. Microbial fuel cells can convert the energy collected in organic compounds into bioelectricity by catalyzing by oxidation. In addition, microorganisms can produce products that can be used as energy sources with their natural metabolic activities. For example, many microorganisms can easily convert carbohydrates into alcohol. However, microbial fuel technologies have advantages such as reliability, high efficiency, cleanliness, and producing minimal or completely non-toxic by-products. Due to these advantages, the use of microbial fuel technology as an alternative source for renewable energy production is among the advanced technological bioprocesses recently. The aim of this study is to highlight the key points of biofuel and bioenergy production techniques with the use of microorganisms and to examine the benefits of energy production by microbial bioprocesses.
\end{abstract}

Anahtar Kelimeler: Biomass, Biofuel, Metabolic Engineering, Bioenergy, Renewable Energy. 


\section{Giriş}

Artan kentleşme ve sanayileşmeye yol açan aşırı nüfus artışı nedeniyle dünya çapında çevre kirliliği vakalarında da artış gözlenmektedir. $\mathrm{Bu}$ tür faaliyetler insan uygarlığını yeni bir düzeye getirmiş olsa da, mevcut yenilenebilir olmayan kaynaklar, büyük miktarda atık üretimi ile birlikte hızla tükenmektedir (Chia vd., 2022). Fosil yakıt seviyesindeki hızlı düşüş ve dünya çapında artan enerji ihtiyacı, çevrede artan sera gazı birikimini azaltmak için geleneksel fosil yakıtların yerini alabilecek ikame yakıtların üretilmesini gerektirmiştir (Ramamrthy vd., 2021). Mikroorganizmaların kullanımıyla daha kaliteli yan ürünlerin daha ekonomik olarak oluşumu, maliyetli, toksik ve sürdürülemez olan sentetik kimyasalların kullanımını azaltmak için büyük önem arz etmektedir (Ramamrthy vd., 2021). Bu nedenle, günümüzde verimli ve ekolojik açıdan faydalı yenilenebilir enerji yakıtlarının tespit edilmesi, olumsuz iklim sorunlarını azaltmak için geleneksel yakıtları anında ikame etme yeteneğini gösteren dünya çapında ana gereksinimdir (Kumar ve Kumar, 2017). Biyokütle ve biyolojik kalıntılardan yenilenebilir enerji kaynakları üretmek için çok yönlü mikroorganizmaların kullanılması daha büyük önem taşımaktadır, bu nedenle günümüzde mikroorganizmaların aracılığıyla farklı biyoyakıtların sentezine yönelik odaklanma artmaktadır (Guimaraes, 2012). Bu durum temel olarak, farklı kısımlardan biyoyakıtların üretilmesine izin veren çeşitli mikroorganizmaların metabolik çeşitliliğinden kaynaklanmaktadır (Ramamrthy vd., 2021). Mikrobiyal biyoteknoloji; mikrobiyal kaynaklı karbonhidratların, ligninlerin ve gliserollerin biyoenerji üretimi gibi çeşitli yenilenebilir kaynaklara dönüştürülmesi için mikroorganizmaların ve enzimlerinin kullanıldığı sürdürülebilir biyoprosesler için önemli stratejiler içermektedir (Tanvir vd., 2021). Tarlalarda tarımsal ve endüstriyel atıkların birikmesi zararlı çevre sorunlarına yol açmaktadır (Ramamrthy vd., 2021). Bu sorunu azaltmak için mikroorganizmalar, mikrobiyal fermentasyon yöntemleri gibi çeşitli biyoteknolojik proseslerde büyük ekonomik öneme sahiptir (Ramamrthy vd., 2021). Buna ek olarak, mikroorganizmalar biyoteknolojik kullanım kapasitesine sahip hayati enzim kaynakları oldukları için biyokütlenin ayrı kullanımı veya biyodönüşümde yardımcı olarak kullanımı gibi çok yönlü kullanımları mevcuttur (Tanvir vd., 2021).

Biyoteknolojinin önümüzdeki dönemde enerji kaynaklarına önemli katkısı olabileceği öngörülmektedir. Özellikle fosil yakıt kaynaklarının bulunmadığı ülkeler için, mikroorganizma kullanılarak biyoyakıt üretiminin enerji arzının büyük ölçüde sağlanmasına yardımcı olabileceği ve yenilenebilir enerji üretim biyoproseslerinin Avrupa Birliği tarafından büyük ölçüde desteklenebileceği olumlu bir güvence olarak kabul edilmektedir (Ramamrthy vd., 2021). Biyokütle enerjisinin önde gelen yönleri olan biyodizel ve biyoetanolün yanı sıra biyohidrojen, aynı zamanda günümüz ve gelecekte ekonomik ve yenilenebilir enerji kaynağı için verimli ve uygulanabilir bir alternatif yön olarak kabul edilmektedir (Ramamrthy vd., 2021).

\section{Mikrobiyal Biyoyakıt Üretimi}

Mikrobiyal biyoyakıt üretimini artırmak için tek bir mikroorganizma kullanmak yerine konsorsiyum olarak gruplanan mikroorganizmaların kullanımı tercih edilmektedir. $\mathrm{Bu}$ tür konsorsiyumlar farklı mikroorganizmaları içerebilir örneğin: (i) Lignoselülozik biyokütleyi hidrolize edilmesinde gerekli enzimi sentezlemek için Trichoderma reesei ve Saccharomyces cerevisiae kullanılır, (ii) Scheffersomycs stipitis, sırasıyla heksoz ve pentoz şekerlerinden yararlanmak için kullanılır, (iii) Kombine selüloz ve sorbitol ortamına batırılmış Penicillium echinulatum tarafindan sentezlenen selülaz ve ksilanaz, lignoselülozik biyokütleden biyoetanol oluşumuna yardımcı olabilir, (iv) Anoxybacillus flavithermus suşunun TWXYL3'ten türetilen, termostabil ve alkali stabil olan ksilanaz, ucuz, ekonomik ve yenilenebilir enerji üretimine büyük ölçüde katkıda bulunabilir (Rastogi ve Shrivastava, 2017; Ritter vd., 2013).

Mikrobiyal biyoyakıt üretiminde biyokütle yapısına katılan çeşitli makromoleküller ve bu molekülleri hidrolizle parçalayan mikrobiyal enzimler kullanılmaktadır.

\subsection{Yă̆ Ekstraksiyonu}

Mikrobiyal biyokütle yapısına katılan yağlar önemli biyoyakıt hammaddesi olarak kabul edilmektedir. Yağların temel yapısı yağ asitleri ve gliserolden oluşmaktadır. Yağ asitleri doymuş (nötral) ve doymamış (polar) yăg asitleri olarak ikiye ayrılmaktadır (Elcik ve Çakmakçı, 2017). Doymuş yağ asitlerinde tek bağ bulunurken, doymamış yağ asitlerinde çift bağlar bulunmaktadır (Mubarak vd., 2015). Biyokütlesinde \%20'den fazla miktarda yă̆ içeren mikroorganizmalar yă üreten mikroorganizmalardır (Darcan ve Sarıül, 2015). Son zamanlarda yapılan çalışmalarda biyodizel üretimi için hammadde olarak mikrobiyal yağların kullanılması önerilmektedir (Darcan ve Sarı̈ül, 2015). Bu nedenle çeşitli mikroorganizmaların yağ asiti ester profillerinin belirlenmesine yönelik çalışmalar yapılmıştır. Örneğin, yüksek yağ oranına sahip mikroalglerin yağ asidi profili C12-C22 arasındadır (Halim vd., 2012). Mikroorganizmalardan yağ asitlerinin ekstraksiyon işlemleri fiziksel ve kimyasal yöntemlerle gerçekleşir. Fiziksel yöntemler; mikrodalga yoluyla ekstraksiyon, ultrasonik ekstraksiyon, mekanik sıkıştırıcı kullanılarak yapılan ekstraksiyondur. Kimyasal yöntemler; solvent yardımı ile yapılan ekstraksiyonlar, süperkritik $\mathrm{CO}_{2}$ ekstraksiyonu ve iyonik sıvılar kullanılarak yapılan ekstraksiyonlardır (Elcik ve Çakmakçı, 2017). Çılgın (2015) yapmış olduğu bir çalışmada, mikroalgal yağdan transesterifikasyon metodu ile elde ettiği mikroalg kaynaklı biyodizelin, yüksek motor performansına sahip olmanın yanı sıra çevre açısından diğer yakıtlara göre daha az zararlı emisyonlara sahip olduğunu göstermiştir (Çılgın, 2015).

\subsection{Biyodizel Üretimi}

Biyodizel, ham petrolden türetilen dizel yakıta çok benzer fiziksel ve kimyasal özelliklere (karbon zincir uzunluğu, enerji yoğunluğu ve viskozite) sahiptir ve potansiyel olarak mevcut içten yanmalı motorlarda "düşürme" yakıt olarak kullanılabilir (Tanvir vd., 2021). İçeriğinde trigliserid olan hayvansal ve bitkisel yağlardan üretilen biyodizel, gliserol ve metanolün reaksiyonu sonucu meydana gelmektedir (Harun vd., 2010). Trigliserit molekülünün alkol ve bazın tepkimesi sonucu, yağ esterleri ve gliserin oluşumu gözlenir ve bu dönüşüm reaksiyonuna transesterifikasyon denir (Viegas vd., 2015). Transesterifikasyon reaksiyonunun tamamlanması için, mikrobiyal kütleden çıkarılan yă $60^{\circ} \mathrm{C}^{\prime}$ ye 1 sitılan manyetik 1sitıcıda 80 saat beklemeye alınır ve sonucunda biyodiselgliserinden oluşan iki fazlı karışım elde edilir (Stojkovic vd., 2014). Gliserin yüksek yoğunluğa sahip olduğu için alt fazda, biyodizel de üst fazda bulunur, ayırma hunisi ile ayrılan 
fazlardan damıtma yada flaş buharlaştırma yoluyla alkol geri kazanılır (Özdemir ve Mutlubaş, 2016). Alkol ve sudan uzaklaştırılan ham gliserin, ilaç ve kozmetik endüstrisinde kullanılmaktadır (Sugözü vd., 2010). Biyodizel fazı, içinde bulunan çok az miktarda baz ve sabundan saf su ile yıkanarak nötr hale getirilir ve viskoziteli biyodizel elde edilmiş olur (Özdemir ve Mutlubaş, 2016).
Tablo 1'de dizel ve biyodizel yakıtlarının özellikleri karşılaştırılmıştır. Tablo 1'de de görüldüğü üzere, dizel ve biyodizel yakıtlarının özellikleri birbirine benzemektedir. Biyodizelin alevlenme noktasının daha yüksek olması, taşınma ve depolanma açısından avantaj sağlamaktadır (Viegas vd., 2015; Stojkovic vd., 2014).

Table 1. Dizel ve Biyodizel Yakıtlarının Özellikleri

\begin{tabular}{l|c|c|}
\hline Yakıt Özellikleri & Biyodizel & Dizel \\
\hline Formül & $\mathrm{C}_{19} \mathrm{H}_{35,2} \mathrm{O}_{2}$ & $\mathrm{C}_{12,2} \mathrm{H}_{23,3} \mathrm{~S}_{0,06}$ \\
\hline Molekül Ağırlı̆ıı & 296 & $120-320$ \\
\hline Özgül Ağırlık & $0,87-0,88$ & $0,82-0,86$ \\
\hline Viskozite & 4,3 & $2,5-3,5$ \\
\hline Tutuşma Katsayısı & $>55$ & $49-55$ \\
\hline Alevlenme Noktası & $>100$ & $>55$ \\
\hline Su Miktarı & $<300$ & $<200$ \\
\hline
\end{tabular}

\subsection{Biyohidrojen Üretimi}

Moleküler hidrojenin fotosentetik üretimi, yenilenebilir enerji üretmeye yönelik en umut verici yaklaşımlardan biri olarak kabul edilir. Hidrojen gazı son derece portatiftir ve 10.1 MJ/L'ye (sıvılaştırılmış) eşdeğer $142 \mathrm{MJ} / \mathrm{kg}^{\prime} l 1 \mathrm{k}$ bir 1sıtma değeri içerir. Yandığında son ürün olarak sadece su yayar (Khetkom vd., 2017). Hem oksijensiz hem de oksijenli fototrofik mikroorganizmalar, fotofermentasyon veya $\mathrm{N}_{2}$ fiksasyonunun metabolizması yoluyla güneş enerjisi kullanarak hidrojen üretebilir (Vasiliadou vd., 2018; Bothe vd., 2010). Birçok siyanobakteriyel tür, atmosferik nitrojeni amonyağa $\left(\mathrm{NH}_{3}\right)$ dönüştürür ve nitrojen sabitleme işleminin bir parçası olarak $\mathrm{H}_{2}$ 'yi yan ürün olarak boşaltır. Siyanobakteriler, atmosferik nitrojen yoksa $\mathrm{H}_{2}$ üretimi için karbonhidrat kullanırlar (Alam ve Wang, 2019).

Fototrofik mikroorganizmalardaki hidrojen üretim potansiyeli, suşa özgü enzimatik aktivitelere ve çevresel koşullara bağlıdır (Khetkom vd., 2017). Fotobiyolojik hidrojen üretimi için en yaygın olarak kullanılan mikroalgler ve siyanobakteriler, hücrelerinde önemli miktarda hidrojenaz enzimi içeren Botryococcus, Chlamydomonas, Chlorococcum, Chlorella, Scenedesmus, Synechocystis, Tetraspora, Anabaena ve Nostoc cinsleridir (Eroğlu ve Melis, 2011). Yapilan çalışmalarda farklı türler arasında Chlamydomonas reinhardtii ve Anabaena spp. türlerinin yüksek oranda hidrojen üretimine sahip olduğu bildirilmiştir (Majidian vd., 2018; Bahadar ve Khan, 2013; Borowitzka vd., 2016).

\subsection{Biyoetanol Üretimi}

Biyoetanol, renksiz, berrak ve kendine has kokusu olan bir siv1 olup, glikozun mikroorganizmalar tarafindan fermente edilmesi ile üretilmektedir Melikoğlu ve Albostan, 2011).

Biyoetanol üretim süreçleri, biyokütlenin türüne, mevcudiyetine ve şeker içeriğine göre önemli ölçüde değişiklik göstermektedir (Elcik ve Çakmakçı, 2017). Bu bağlamda

Afrika palmiyesi, muz, pirinç, kakao ve mikroorganizmalar gibi farklı substratlar enerji üretimi için yüksek potansiyele sahip yenilenebilir enerji kaynakları olarak kabul edilmektedir (Noboa vd., 2021).

Biyoetanol üretimin temeli fermantasyon teknolojileridir (İnal, 2011). Biyoetanol daha çok mayalar tarafından üretilir, özellikle Saccharomyces cerevisiae türü bu türün fermantasyon hızının yüksek olması, yüksek toleransa sahip olması ve hızlı çoğalabilmesi tercih edilme sebepleridir (Bengisu, 2014). Biyoetanol fermantasyonunda 1 molekül glikoz metabolize edilerek 2 molekül pirüvata dönüşmektedir (İnal, 2011). Oluşan pirüvat $\mathrm{CO}_{2}$ salınımı ile etanole indirgenir (İnal, 2011). Chen vd. (2021) yapmış oldukları bir çalışmada, Saccharomyces cerevisiae ile \% 90 verim ile biyoetanol üretimi gerçekleştirdiklerini belirtmişlerdir (Chen vd., 2021).

\subsection{Biyogaz Üretimi}

Biyogaz tipik olarak \% 45-70 metan, \% 20-55 $\mathrm{CO}_{2}$ ve ayrica az miktarda $\mathrm{H}_{2} \mathrm{~S}, \mathrm{H}_{2} \mathrm{O}$ ve hidrokarbondan oluşur (Zabed vd., 2021). Biyogaz biçimindeki yeşil enerji, anaerobik parçalanma gibi yerleşik teknolojilerle fototrofik mikroorganizmalardan üretilebilmektedir. Hem tamamıla biyokütle hem de lipitten ekstrakte edilen biyokütle, biyogaz üretimi için kullanılabilmektedir (Tanvir vd., 2021). Güçlü biyogaz üreten mikrobiyal fototroflar, yüksek büyüme hızına, düşük holoselüloz içerikli ince hücre duvarına, daha yüksek çevresel uyarlanabilirliğe ve gelişmiş sindirim verimliliği ve metan içeriği için daha fazla sitoplazmik bileşene sahip olmalıdır (Tijani vd., 2015). Anabaena cylindrica, Chlorella sorokiniana, Scenedesmus obliquus, Spirulina platensis ve Synechococcus sp.türleri önceden belirtilen kriterlere göre en fazla biyogaz üreten türler olarak tanımlanmıştır (Bose vd., 2019).

Anaerobik parçalanma; hidroliz, asit oluşumu ve metan oluşumu olmak üzere 3 aşamada meydana gelir (Speece, 1996). Hidroliz aşamasında, organik moleküller mikroorganizmaların hücre dişı enzimleri ile daha küçük ve daha basit yapılı moleküllere dönüşmektedir; asit oluşumu aşamasında,organik moleküller valerik asit, bütirik asit, propiyonik asit ve asetik asit gibi organik asitlere, ve metanola, çözünmüş karbonhidratlar etanol, $\mathrm{H}_{2}$ ve $\mathrm{CO}_{2}$ 'e, amino asitler, süksinik asit ve $\mathrm{H}_{2}$ 'e, yağ asitleri ise asetat ve $\mathrm{H}_{2}$ 'e dönüşmektedir; metan oluşum aşamasında ise asit oluşum aşamasında oluşan organik asitler, $\mathrm{H}_{2}$ ve asetat, metan oluşturan mikroorganizmalar tarafından kullanılmakta ve biyogaza dönüştürülmektedir (Speece, 1996). 
Üretilen biyogazın genellikle elektrik üretimi için kullanılırlığı yaygındır Chia vd., 2022).

\section{Sonuçlar}

$\mathrm{Bu}$ çalışmada, çeşitli mikroorganizmalar kullanımı ile biyoyakıt ve biyoenerji üretim tekniklerinin kilit noktaları vurgulanmış ve mikrobiyal biyoproseslerle enerji üretiminin faydaları incelenmiştir. Dünyanın artan enerji ihtiyacını karşılayabilmek için yenilenebilir ve sürdürülebilir enerji ve yakıtların üretimi son derece önem arz etmektedir. Mikrobiyal yakıt hücreleri doğal fotosentetik faaliyetleri ile hidrojen, fermantasyon yolu ile biyoetanol, anaerobik parçalanma ile biyogaz üretebilmektedirler. Mikrobiyal yakıt teknolojileri güvenilirliği, yüksek verimliliği, çevre dostu olması ve minimum düzeyde toksik veya tamamen toksik olmayan yan ürünler üretmesi gibi avantajlara sahiptir. $\mathrm{Bu}$ avantajlar nedeniyle yenilenebilir enerji üretimi için alternatif bir kaynak olarak mikrobiyal yakıt teknolojisinin kullanılması son dönemlerde ileri teknolojik biyoprosesler arasında tercih edilmektedir.

\section{Kaynakça}

Alam, M.A., Wang, Z. 2019, Microalgea Biotechnology for Development of Biofuel and Wastewater Treatmen, 1st ed., Singapore: Springer.

Bahadar, A., Khan, M.B. 2013, Progress in energy form microalgea: A review, Renewable and Sustainable Energy Reviews, 27:128-148.

Bengisu, G. 2014, Alternatif Yakıt Kaynağı Olarak Biyoetanol, Alınteri Zirai Bilimler Dergisi, 27:43-52.

Borowitzka, M.A., Beardall, J., Raven, J.A. 2016, The Physiology of Microalgea, 1st ed., Switzerland: Springer.

Bose, A., Lin, R., Rajendran, K., O'Shea, R., Xia, A., Murphy, J.D. 2019, How to optimise photosynthetic biogas upgrading: a perspective on system design and microalgea selection, Biotechnology Advances, 37.

Bothe, H., Schmitz, O., Yates, M.G., Newton, W.E. 2010, Nitrogen Fixation and Hydrogen Metabolism in Cyanobacteria, Microbiology and Molecular Biology Reviews, 74:529-551.

Chen, Z., Niu, Y., Chen, C., Li, H. 2021, Optimization of bioethanol fermentation productivity in Saccharomyces cerevisiae by regulation of social behavior, Chemical Engineering Science, 246.

Chia, S.R., Nomanbhay, S.B.H.J.M., Chew, K.W., Munawaroh, H.S.H., Shamsuddin, A.B.D.H. , Show, P. L. 2022, Algae as potential feedstock for various bioenergy production, Chemosphere, 287.

Çılgın, E. 2015, 3. Nesil Biyoyakıt Teknolojisi Alglerin bir Dizel Motorunda Performans ve Egzoz Emisyonlarına Etkisinin Araştırılması, Iğdır Üniversitesi Fen Bilimleri Enstitütüsü Dergisi, 3:33-41.

Darcan, S., Sarıül, N. Mikroorganizmalardan Tek Hücre Yağları Üretimi, Türk Mikrobiyal Cem Derg., 45:55-67.

Elcik, H., Çakmakçı, M. 2017, Mikroalg üretimi ve mikroalglerden biyoyakıt eldesi, Journal of the Faculty of Engineering and Architecture of Gazi University, 32:795820.

Eroğlu, E., Melis, A. 2011, Photobiological hydrogen production: Recent advances and state of the art, Bioresource Technology, 102:8403-8413.

Guimaraes, L.H.S. 2012, Carbohydrates from Biomass: Sources and Transformation by Microbial Enzymes, INTECH Open Access Publisher.
Halim, R., Danquah, M.K., Webley, P.A. 2012, Extraction of oil from microalgea for biodiesel production: A review, Biotechnology Advances, 30:709-732.

Harun, R., Singh, M., Forde, G.M., Danquah, M.K. 2010, Bioprocess engineering of microalgea to produce a variety of consumer products, Renewable and Sustainable Energy Reviews, 14:1037-1047.

İnal, M. 2011, Sodyum Aljinat-Aş1-Poli (N-Vinil-2Pirolidon)'a İmmobilize Edilmiş Bazı Maya Türlerinden Biyoetanol Üretimi, Kimya Anabilim Dalı Doktora Tezi, Kırıkkale Üniversitesi, Kırıkkale.

Khetkorn, W., Rastogi, R.P., Incharoensakdi, A., Lİndblad, P., Madamwar, D., Pandey, A., Larroche, C. 2017, Microalgal hydrogen production - A review, Bioresource Technology, 243:1194-1206.

Kumar, R., Kumar, P. 2017, Future Microbial Applications for Bioenergy Production: A Perspective, Frontiers in Microbiology, 8.

Majidian, P., Tabatabaei, M., Zeinolabedini, M., Naghshbandi, M.P., Chisti, Y. 2018, Metabolic engineering of microorganisms for biofuel production, Renewable and Sustainable Energy Reviews, 82:3863-3885.

Melikoğlu, M., Albostan, A. 2011, Türkiye'de Biyoetanol Üretimi ve Potansiyeli, Gazi Üniversitesi Mühendislik ve Mimarlık Fakültesi Dergisi, 26:151-160.

Mubarak, M., Shaija, A., Suchithra, T.V. 2015, A review on the extraction of lipid from microalgea for biodiesel production, Algal Research, 7:117-123.

Noboa, J.D., Bernal, T., Solar, J., Pena, J.A. 2021, Kinetic modeling of batch bioethanol production form CCN- 51 Cocoa Mucilage, Journal of the Taiwan Institue of Chemical Engineers, 16.

Özdemir, Z. Ö., Mutlubaş, H. 2016, Biyodizel Üretim Yöntemleri ve Çevresel Etkileri, Kirklareli University Journal of Engineering and Science, 2:129-143.

Ramamurthy, P.C., Singh, P., Kapoor, D., Parihar, P., Samuel, J., Prasad, R., Kumar, A., Singh, J. 2021, Microbial biotechnological approaches: renewable bioprocessing for the future energy systems, Microbial Cell Factories, 20.

Rastogi, M., Shrivastava, S. 2017, Recent advances in second generation bioethanol production: An insight to pretreatment, saccharification and fermantation processes, Renewable and Sustainable Energy Reviews, 80:330-340.

Ritter, C.E.T., Camassola, M., Zampieri, D., Siveria, M.M., Dillon, J.P. 2013, Cellulase and Xylanase Production by Penicillium echinulatum in Submerged Media Containing Cellulose Amended with Sorbitol, Enzyme Research, 6.

Speece, R.E. 1996, Anaerobic biotechnology for industrial wastewater treatment, Environmental Science and Technology, 17:416-427.

Stojkovic, I. J., Stamenkovic, O.S., Povrenovic, D.S., Veljkovic, V.B. 2014, Purification technologies for crude biodiesel obtained by alkali-catalyzed transesterification, Renewable and Sustainable Energy Reviews, 32:1-15.

Sugözü, İ., Öner, C., Altun, Ş. 2010, The Performance and Emissions Characteristic of a Diesel Engine Fueled with Biodiesel and Diesel Fuel, Int.J.Eng.Research \& Development, 2: 50-53.

Tanvir, R.U., Zhang, J., Canter, T., Chen, D., Lu, J., Hu, Z. 2021, Harnessing solar energy using phototropic microorganisms: A sustainable pathway to bioenergy, biomaterials, and environmental solutions, Renewable and Sustainable Energy Reviews, 146. 
Tijani, H., Abdullah, N., Yuzir, A. 2015, Integration of microalgea biomass in biomethanation systems, Renewable and Sustainable Energy Reviews, 52:1610-1622.

Vasiliadou, I., Berna, A., Manchon, C., Melero, J.A., Martinez, F., Núñez, A.E., Puyol, D. 2018, Biological and Bioelectrochemical Systems for Hydrogen Production and Carbon Fixation Using Purple Phototrophic Bacteria, Frontiers in Energy Research, 6.

Viegas, C.V., Hachemi, I., Freitas, S.P., Arvela, P.M., Aho, A., Hemming, J., Smeds, A., Heinmaa, I., Fontes, F.B., Pereira, D.C.S., Kumar, N., Aranda, D.A.G., Murzin, D.Y. 2015, A route to produce renewable diesel from algea: Synthesis and characterization of biodiesel via in situ transesterification of Chlorella alga and its catalytic deoxygenation to renewable diesel, Fuel, 155:144-154.

Zabed, H.M., Akter, S., Yun, J., Zhang, G., Zahng, Y., Qi, X. 2020, Biogas from microalgea: Technologies, challenges and oppurtunities, Renewable and Sustainable Energy $\mathrm{R}$

e

V 